\title{
Journal of Management Sciences \\ Psychological Safety: A Cross-level Study of a Higher Educational Institute (HEI)
}

\section{Affiliation:}

Alam Sher

Department of Management Sciences, Institutes of Management Sciences,

Peshawar. Email: alamsher136@gmail.com

Shabana Gul

Department of Management Sciences, Institutes of Management Sciences, Peshawar

Muhammad Khan Riaz

Department of Management Sciences, COMSATS University Islamabad,

Attock Campus.

Muhammad Naeem

Department of Management Sciences, Institute of Management Sciences, Peshawar.

\section{Manuscript Information}

Submission Date: November 15, 2018

Acceptance Date: February 25, 2019

\section{Citation in APA Style:}

Sher, A., Gul, S., Riaz, M. K., \& Naeem, M. (2019). Psychological Safety: A Crosslevel Study of a Higher Educational Institute (HEI), Journal of Management Sciences, $6(1), 30-49$.

DOI: https://doi.org/10.20547/jms.2014.1906103 


\title{
Psychological Safety: A Cross-level Study of a Higher Educational Institute (HEI)
}

\author{
Alam Sher* $\quad$ Shabana Gul ${ }^{\dagger} \quad$ Muhammad Khan Riaz ${ }^{\ddagger} \quad$ Muhammad Naeem ${ }^{\S}$
}

\begin{abstract}
This study examines the relationships between antecedents of psychological safety at the individual, group and organizational level. The data was collected from a sample of eighty-four employees (i.e. teachers and non-teachers) working in a higher education institute (HEI) of Khyber Pakhtunkhwa by using a structured questionnaire. The data is analyzed with the help of correlation and regression analyses. The findings indicate that the individual level antecedents had a positive relationship with psychological safety except for adherence to norms, whereas both the group and organizational level antecedents were positively related with psychological safety. The study also discusses implications, limitations and future directions.
\end{abstract}

Keywords: Psychological safety, cross-level analysis, HEI, measurement, antecedents.

\section{Introduction}

In today's business environment, several organizations exist with narrowing expertise and intricate job structures. Employees are increasingly required to contribute to the improvement of organizational practices to enable learning through voicing and experimenting with new ideas (A. Edmondson, 1999). These activities may have potential benefits for the organization, but they bring certain risks for individual employee, e.g. voicing a new idea may challenge the existing norms, system or ways through which work is carried out or conflict with the interest of other organizational members (A. C. Edmondson, Bohmer, \& Pisano, 2001). Additionally, experimenting with new and innovative ideas may not be successful in the end, be viewed as a failure and consequently leading to the employees involved to be viewed in a negative light (Van Dyne \& LePine, 1998). The characteristics of a psychologically safe workplace include (1) employees voicing new ideas (2) seeking and providing feedback (3) willingly taking a risk and (4) collaborating in a way to overcome threats to individual, group as well as organizational learning (A. Edmondson, 1999). Organizational research determined psychological safety to be critically important in developing an understanding of how employees achieve their goals either individually or in a group (A. Edmondson, 1999). The degree to which an employee can accomplish his work depends on the level of uncertainty and interpersonal risk prevalent in an organization (Chen, Liao, \& Wen, 2014). Employees need to contend with various

\footnotetext{
*Department of Management Sciences, Institutes of Management Sciences, Peshawar. Email: alamsher136@gmail.com

${ }^{\dagger}$ Department of Management Sciences, Institutes of Management Sciences, Peshawar. E-mail: shabana.gul@imsciences.edu.pk

${ }^{\ddagger}$ Department of Management Sciences, COMSATS University Islamabad, Attock Campus.

$\S$ Department of Management Sciences, Institute of Management Sciences, Peshawar.
} 
characteristics of interpersonal risk and uncertainty. These two influence an employee's cognition, behavior and emotions, hence higher levels of uncertainty and interpersonal risk reduce trust and safety among employees (Thau, Bennett, Mitchell, \& Marrs, 2009). Psychological safety is an important concept in an era of exponential growth of knowledge and the rise of teamwork. Consequently, new work relations are developed, requiring the employees to integrate their different perspectives, share their ideas and information and collaborate with organizational members to achieve shared organizational goals (A. C. Edmondson \& Lei, 2014). In psychologically safe work environments, employees perceive that if they commit a mistake or ask ignorant questions other will not view them negatively.

Psychological safety in an educational setup is a condition of an environment which is free from psychological violence in daily interactions among the people. There it contributes to the satisfaction of the needs for interpersonal trust, communication and creates a sense of belongingness. The type of interaction among the people in the educational environment develops the reference environment, their satisfaction with the components of their interactions, and the psychological safety of the members (Bordovskaia \& Baeva, 2015). Though psychological safety is an important concept in today's work environments, especially in an educational environment; studies have been conducted in sectors like healthcare, manufacturing etc. with very little attention to the education sector. Therefore, this study contributes to the body of literature by examining psychological safety in a higher education institute (HEI).

Investigating the antecedents of psychological safety and their relationships with each other in an HEI is critical to both employees and the management because it will help the management and employees of the HEI to better understand which policies or processes to implement in their workplace for developing a psychologically safe environment, subsequently, it will allow the employees to feel secure in speaking up and not worry about consequences, thus, directly affecting the organizational performance and learning. Extensive research on psychological safety has been conducted mostly at the individual and group level of analysis (Detert \& Burris, 2007; Roussin \& Webber, 2012). However, this study attempts to conduct a cross-level analysis of the antecedents of psychological safety in an educational sector. The objective of this study is to investigate the antecedents of psychological safety and relationships among these antecedents. Additionally, it will also compare the identified antecedents of psychological safety at individual, group and organizational level.

\section{Literature Review}

\section{Individual-level Psychological Safety}

Psychological safety was explored by organizational researchers as early as the 1960s.However research on psychological safety languished till early 1990s when it experienced a renewed interest (A. C. Edmondson, Kramer, \& Cook, 2004). E. H. Schein and Bennis (1965) proposed that psychological safety is important to make the individual feel safe and fully 
capable for them to change his/her behavior in response to organizational challenges. Fundamentally, psychological safety is about removing the interpersonal risk which accompanies organizational change and uncertainty (E. H. Schein \& Bennis, 1965). It allows the employees to overcome the learning anxiety and defensiveness which occur if the employees are presented with statistical data that may contradict their preconceived hopes or expectations. Psychological safety allows the individual to forsake self-protection and work towards achieving shared goals and problem-solving (E. Schein, 1985).

Kahn (1990) stated that psychological safety influences the individual employee's willingness to express themselves physically, emotionally and cognitively while performing their work roles, rather than withdrawing or disengaging and defending their own selves. Individuals develop beliefs that they will be awarded the benefit of the doubt (psychological safety's defining characteristic) when relationships are characterized by mutual respect and trust (Kahn, 1990). Whereas, Roussin and Webber (2012) opens that psychological safety increases an employee's job engagement, improves an individual's performance and learning and reduces the individual's tendency to commit unpromising decisions. Psychological safety is one factor in the organizational environment that is learned and adopted by the members when they start socializing in the work environments. Additionally, they found that psychological safety can act as a mediated moderator to effect individual performance and other outcomes at the individual level.

\section{Antecedents of Psychological Safety at the Individual Level}

\section{Inclusive Leadership}

Inclusive leadership refers to leaders that display accessibility, openness, and availability while interacting with their followers (Carmeli, Reiter-Palmon, \& Ziv, 2010). Nembhard and Edmondson (2006); A. C. Edmondson (2004) stated that inclusive leadership are leadership behaviors which (1) invite inputs from their followers help shape the members believe that they are being valued and (2) allowing followers to openly share their opinions and views by being available, open and accessible to them. These Leadership behaviors contribute to a person's feeling of psychological safety. Especially when leaders display availability, openness, and accessibility they are likely to further the development of psychological safety in the workplace. Leaders can embolden the employees to come up with new ideas and take risks through communicating the importance of these behaviors and help the employees to understand that they will not face any negative consequences in this course of action (Carmeli et al., 2010). Moreover, it was found that there is a positive relationship between inclusive leadership and psychological safety. Based on the above discussion, the following hypothesis is developed:

Hypothesis 1a: Inclusive leadership will be positively affecting the psychological safety.

\section{Interpersonal Relationships}

Interpersonal relations between employees who are trusting and supportive of each other foster psychological safety (Kahn, 1990). Interpersonal relationships are characterized by 
interpersonal trust. Interpersonal trust can be either affective or cognitive. Affective trust concerns the emotional relationship among the individuals whereas cognitive trust refers to the dependability and reliability of others. Employees who trust each other usually express greater concern for others welfare and have a strong belief in the intrinsic value of interpersonal relations (McAllister, 1995). May, Gilson, and Harter (2004) examined how affective and supportive trust-building interpersonal relations leads to higher psychological safety. They concluded that there is a significant and positive association between interpersonal relations and psychological safety. Based on the above discussion, the following hypothesis is developed.

Hypothesis 1b: Interpersonal relationships will positively impact psychological safety.

\section{Adherence to Norms}

At the individual level, individual differences such as co-worker norms are strongly associated with psychological safety (May et al., 2004). Norms within the organizations tend to regulate attitudes, behaviors and the psychological dimensions of work. Kahn (1990) argues that individual employees who remain within the boundary of appropriate behaviors will feel safer at work. Norms are the informal rules that individuals adopt to regularize and govern organizational members' behavior (Feldman, 1984). Norms are usually theorized if; they make the expected behavior of individual/group members more predictable, help avoid ignominious interpersonal problems and facilitate individual/group survival (May et al., 2004). Although norms serve these important processes, however, creating control mechanisms to enforce norms can have very negative consequences for individuals within and outside the group (Barker, 1993). Similarly, A. Edmondson (1999) maintains that strong cohesion between individuals and group members decreases the willingness of employees to disagree or challenge views of others, suggesting a lack interpersonal risk-taking i.e. psychological safety. Although norms might create structural boundaries to ensure appropriate behaviors (Kahn, 1990), however, May et al. (2004) suggested that individuals who are expected follow existing norms may cause them to feel less psychologically safe as compared to when individuals have more behavioral flexibility. Based on the above discussion, the following hypothesis is developed:

Hypothesis 1c: Adherence to norms will be negatively affecting the psychological safety.

Hypothesis 1d: Inclusive leadership and interpersonal relationships will be positively related with one another, whereas adherence to norms will be negatively related to inclusive leadership and interpersonal relationships.

\section{Group-level Psychological Safety}

Today's organizations are increasingly using teams to achieve their organizational goals which faces considerable risk and uncertainty (Wheelwright, 1994). The members of a 
team must embrace the process of risk-taking, experimenting with new ideas and often experience failures while collaborating with other group/team members, navigating differences in status, experience, and discipline among other factors. These differences require interpersonal skill and a psychologically safe work environment (Mogelof \& Edmondson, 2006).

When members of a team feel that their ideas and opinions are valued and appreciated, they are likely to cooperate with one another and encourage a sense of responsibility for their team outcomes. This increase of social influence encourages the members to engage in mutual leadership (Hans \& Gupta, 2018).

A. Edmondson (1999) defines team psychological safety as taken for granted beliefs or assumption held by team members that other members will respond favorably if they express their thoughts, by asking questions, asking for feedback, notifying a mistake, or proposing new ideas. Although these activities are important for proper functioning of a team especially in case of innovation, however, engaging in such activities is very risky for those individuals that may be perceived by others as disruptive, ignorant, or in worst case even incompetent. Consequently, many employees try to manage this risk to minimize harm to their self-image. Team psychological safety allows the group members to feel relaxed around one another and openly engage in behaviors that enable learning. A psychologically safe environment does not refer to a homely environment, where employees are close friends; neither does it suggest that there are no problems or pressure. It is different from group cohesiveness which reduces an employee's willingness to disagree and does not allow the challenging of ideas (Janis, 1982). It describes an environment which is characterized by trust and respect and that the employees are comfortable in being themselves and openly expressing themselves (A. Edmondson, 1999). Mutual trust and support from leaders and colleagues will be beneficial for building self-worth. Trust, team support and a safe psychological climate will help team members not worry about consequences from taking interpersonal risk, such as censure, ridicule, scolding and neglect (Liu, Zhang, Liao, Hao, \& Mao, 2016).

\section{Antecedents of Psychological Safety at the Group Level}

\section{Affect-Based Trust}

According to A. C. Edmondson (2004), teams with high psychological safety are distinguished by interpersonal trust, respecting team member competence and caring about team members as people. She noted that trust displayed by team members toward their leader is not due to rational expectation rather such trust is developed in a relational way i.e. choices are intuitive and affective instead of calculative. McAllister (1995) described affect-based trust as an emotional bond between individuals. Emotional investments are made by an individual, they express greater concern and care for others, believe in the intrinsic value of these relations. Essentially, the emotional ties that link individual together provide a basis for trust (ibid).

When members of a team and their leader have a strong emotional connection, this influences the performance of the team through the influence of team psychological safety. 
This trust relates to the expectations of the team members that the leader will allow and respect the member's opinions while not fearing any retribution or consequences either from the leader or other members (Schaubroeck, Lam, \& Peng, 2011). Thus, it can be said that, higher the trust that team members have for the leader the higher levels of psychological safety they feel. Based on the above discussion, the following hypothesis is developed:

Hypothesis 2a: Affect-based trust will be positively related to psychological safety.

\section{Team Autonomy}

An important task design decision in any project involves deciding the level of autonomy in decision making allowed to the team members. Teams with higher levels of autonomy allow the team members to manage, plan, assign jobs, schedule work, take service or production-related decisions, and take immediate action when problems arise. Moreover, due to high autonomy team members feel the freedom to make day-to-day project decisions without any external supervision (Stewart, 2006). According to Hans and Gupta (2018) psychological safety has a positive effect on team autonomy. Autonomy provides the team members with discretion in conducting their work, however, high levels of freedom may create interpersonal risks and have a negative effect on the members especially in the absence of a psychologically safe environment (ibid).

Team autonomy influences psychological safety by two different mechanisms. First, greater responsibility to make routine project decisions creates a greater initiative in the group members and creates direct and open communication between team members. Hence, members of a team do not necessarily have to wait for their manager's permission or guidance while engaging in important risk-taking activities and members can freely and openly exchange their views one another without fearing any punishment or reprisal by their project leader (Chandrasekaran \& Mishra, 2012). Secondly, members of a team are usually aware of a project's ground realities, higher team autonomy allows the members to take critical decisions and organize a coordinated response to execution challenges faced by the project. Such a coordinated response eliminates opportunities to apportion individual blame between team members, raise their perceptions regarding one another's competence and integrity and increasing their psychological safety.

Chandrasekaran and Mishra (2012) studied psychological safety and group autonomy as antecedents to group performance. They argue that higher autonomy in teams was associated with a higher level of psychological safety. Particularly it showed that increasing psychological safety reduces the group turnover and improves the performance of research and development teams. Based on the above discussion, the following hypothesis is developed:

Hypothesis 2b: Team autonomy will be positively influencing psychological safety. 


\section{Inclusive Leadership}

Nembhard and Edmondson (2006) defined inclusive leadership as words and actions by a leader that demonstrates appreciation and invitation for their follower's contribution. Inclusive leadership captures the efforts of the leader to include the team members in decisions and discussions in which their perspectives and voices may otherwise be absent. The construct of inclusive leadership is related to the coaching behavior of the team leader, which describes those behaviors of the team leader that facilitate group process, provide feedback and clarification (A. Edmondson, 1999), and is also related to participative leadership which describes team leaders that consult with their employees, takes part in shared decision-making and delegates the authority to make decisions to his subordinates (Bass \& Stogdill, 1990). However, inclusive leadership differs from these concepts in that it is directly concerned with situations that are characterized by power differences and concerns more narrowly to only those behaviors that acknowledge and invite other opinions and views. Inclusive leadership describes behaviors which through direct invitation will positively influence psychological safety in the team and help them in speaking up (Nembhard \& Edmondson, 2006). Finally, Roussin (2008) argues that the more a leader used, "dyadic discovery methods" (exploratory sessions between the group leader and group members) promoted group performance and psychological safety. Based on the above discussion, the following hypothesis is developed:

\section{Hypothesis 2c: Inclusive leadership will be positively influencing psychological safety.}

\section{Team Structure}

Team structure is a combination of three core elements i.e. specialization, hierarchy, and formalization. A highly structured team has an intricate division of labor horizontally (specialization) as well as vertically (hierarchy) with very clear procedures for prioritizing and coordinating work (formalization) (Bunderson \& Boumgarden, 2010).

High clarity in roles, priorities and procedures and authority makes the team member interactions and relations very predictable and removes uncertainty in their relationships which foster intra group trust (A. C. Edmondson, 2004). Members of a team interact more when there is high clarity on the roles that each team member must play, on the procedures and rules that govern coordination and on the distribution of authority and how it is exercised. In this way, team structure lowers the team member defenses and creates a psychologically safe climate in the team (Bunderson \& Boumgarden, 2010). Thus, it can be hypothesized that,

Hypothesis 2d: Team structure will be positively related to psychological safety.

\section{Organizational Context Support}

According to Wageman (1996) some structural characteristics of team design- clear team goals, team leader behavior and organizational context support such as information, adequate resources, and rewards have been proven to increase the effectiveness of a team. 
The extent to which a team receives context support from the organization may be positively related to the level of psychological safety in that team. Access to adequate and key resources and information eliminates the insecurity of the team members and reduces their defensiveness, such as caused by the member's concerns regarding unfair resource distribution within the team as well between the organization's teams (A. Edmondson, 1999). Thus, it can be postulated that, safety.

Hypothesis 2e: Organizational context support will be positively influencing psychological

Hypothesis 2f: There will be a positive relationship between all the group level antecedents.

\section{Organizational-level Psychological Safety}

Baer and Frese (2003), concept of psychological safety was analyzed at individual and group/team level. They extended A. Edmondson (1999)'s concept of team psychological safety to an organizational climate for psychological safety. They argued that a psychologically safe organizational climate refers to the formal and informal practices, processes and procedures of the organization which guides and supports trustful and open interactions at workplace. Hence, a psychologically safe climate describes an environment in which employees feel safe to express their perspective without worrying about harm$\mathrm{ful} /$ negative reaction by other organizational colleagues. Employees in a supportive climate are highly likely to take an interpersonal risk by proposing new and innovative ideas or challenge existing organizational norms than an environment in which expressing new ideas or challenging something might lead negative consequences (West, 1990).

Brown and Leigh (1996) extended Kahn (1990)'s definition of psychological safety as "a person's feelings that if he/she express themselves and their ideas they will not face retaliation from their peers" (p.708). They stated that organizational psychological safety is an employee's perception regarding three dimensions of climate, the extent to which the: (1) management is perceived to be supportive and flexible and the feelings of the employees that they have control over their work, as well as the methods used to accomplish it, (2) the roles and norms of the organization, are perceived to be clear, and (3) employees feel safe to show their feelings and core aspects of their self in their work. When the employees believe that their behavior will not receive hostile evaluations from other members, they will put more time and effort into their work and be more willing to participate in organizational affairs (Liu et al., 2016).

\section{Antecedents of Psychological Safety at the Organizational Level}

\section{High-Quality Relationships}

Interpersonal relations in the organization have a significant effect on the people, how they engage in social behaviors and on core processes like error detection and coordination. In the context of the workplace, high-quality relationships are important channels 
that allow the members of the organization to engage in meaningful learning behaviors and achieve the organizational goals (Weick \& Roberts, 1993).

Dutton and Heaphy (2003) proposed two different clusters of relationship characteristics that capture the differences in the quality of the relationships. The two clusters along with their other dimensions are intended to capture a complete set of characteristics around which the relationships may vary. Characteristics of the interpersonal relationships among the individuals are captured by the first cluster i.e. (capacities of high-quality relationships) while the experiences of the individual in a relationship are captured by the second cluster (experiences of high-quality relationships). The capacities of high-quality relationships enable the individuals to exchange more varied ideas and information that are important for creating solutions for problems and innovative ways to enhance work process (Carmeli, Brueller, \& Dutton, 2009).

\section{Capacities of High-quality Relationships}

\section{Emotional Carrying Capacity}

When interpersonal relationships have higher emotional carrying capacity it is reasonable for individuals to express various emotions in their relationships, which increases the probability of both the individuals being understood (Dutton \& Heaphy, 2003). A higher capacity to communicate emotions in a relationship develops psychological safety because the individuals feel freedom in expressing various emotions without the fearing interpersonal consequences (e.g. embarrassment). In high-quality relationships individuals can also display negative emotions, hence are highly likely to speak up without the fear of retribution (Carmeli et al., 2009).

\section{Tensility}

Dutton and Heaphy (2003) state that high-quality relations have high tensility which allows the relationship to withstand conflict and stress and recover from setbacks. Tensility refers to the flexibility of a relationship. Thus, the relationships tensility to withstand challenges and conflicts is a very important quality that influences the individual's perception of psychological safety (Carmeli et al., 2009).

\section{Connectivity}

Connectivity captures the extent of openness of a relationship to new ideas and the capacity to deflect those behaviors that obstruct generative processes. Connectivity facilitates non-defensive reactions and allows the members of a relationship to be open to new challenges and be able to speak up about them. Conversely, lower connectivity makes the individuals afraid to speak out, indicating lower psychological safety (Carmeli et al., 2009). 


\section{Experiences of High-Quality Relationships}

\section{Positive Regard}

The individual in a high-quality relationship have a deep contact with one another and they experience the feeling of being respected by the people, even if the duration of the relationship is short. When the employees interact respectfully with one another, they present an image that is both valued and positive. Thus, when individuals feel they are valued and appreciated, they are highly likely to speak up (psychological safety) without fearing consequences (Carmeli et al., 2009).

\section{Mutuality}

Mutuality refers to the state in which the individuals in a relationship are actively participating and are fully engaged. Mutuality increases the individual's willingness to disclose mistakes to their managers and a manager's appreciation of mutuality helps create safety for the individuals (Dutton \& Heaphy, 2003). Thus, when mutuality in a relationship is high, there is higher mutual empathy, that fosters psychological safety. Similarly, Carmeli et al. (2009) argues that positive and high-work relationship experiences are necessary to foster psychological safety. Based on the above discussion the third set of hypotheses are:

Hypothesis 3a: Capacities of high-quality relations will be positively associated with psychological safety.

Hypothesis 3b: Experiences of high-quality relations will be positively associated with psychological safety.

\section{Research Methodology}

\section{Research Design}

The research design used in the current study is quantitative research and the data were gathered through survey method. According to Yin (1993), quantitative surveys can provide the information and explanations regarding a variable that are 'adequate at the level of meaning.

\section{Population and Sampling Technique}

The study population was comprised of employees of an HEI at Khyber Pakhtunkhwa. Stratified random sampling was utilized to draw a sample with two strata i.e. teaching staff and non-teaching staff. As the total population consists of 180 employees a fifty percent proportionate sample was taken with a sample size of $90(n=90)$. 


\section{Data Collection}

Ninety employees of the HEI were selected to participate in this study. They were employed as faculty members and departmental employees in the HEI. The self-administered questionnaires were completed on-site by the respondents. Of the total surveys, 84 were returned, (response rate of 93\%). Gender wise, $85.7 \%(n=72)$ respondents were males and $14.3 \%(n=12)$ were females. Profession wise, $56 \%(n-47)$ respondents were teachers and $44 \%(n=337)$ were non-teachers. All three questionnaires i.e. individual, group and organizational were presented to every respondent to complete.

\section{Figure 1}

The Conceptual Framework of the Study - Network of antecedents related to psychological safety based on the literature review

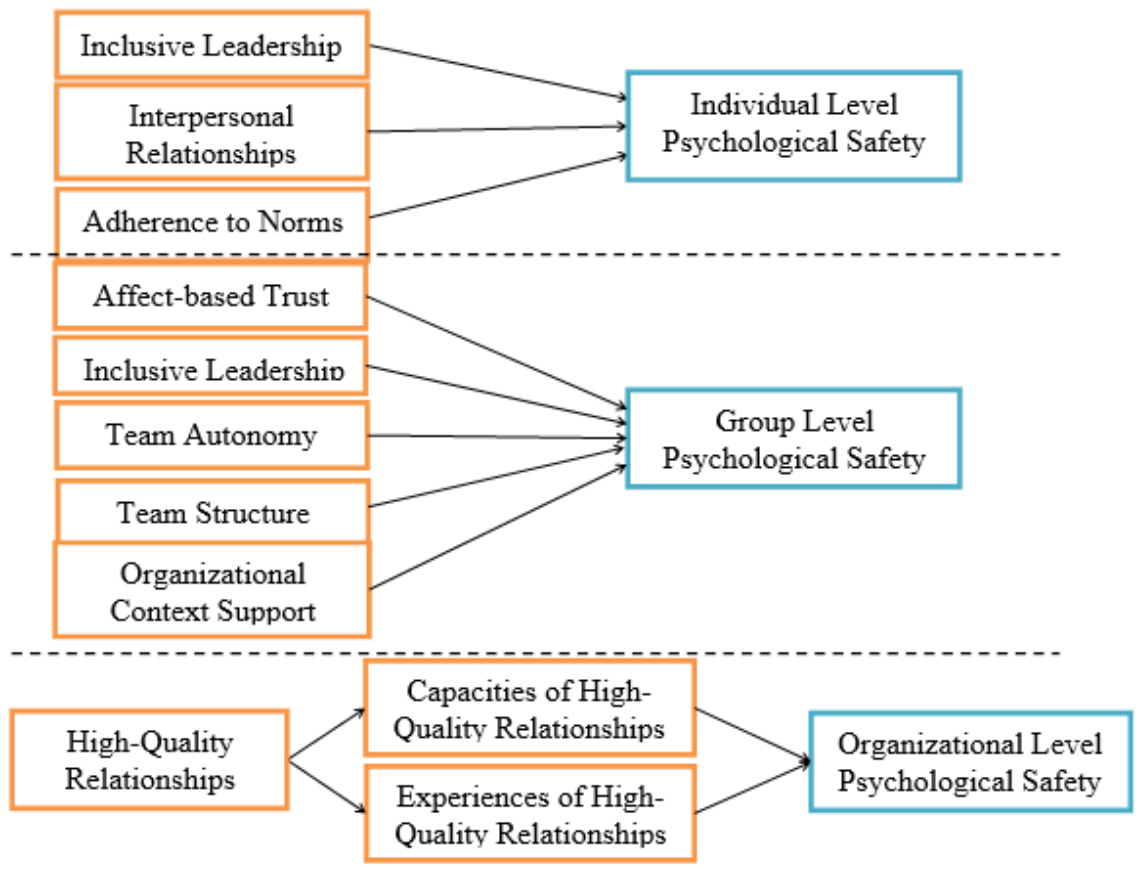

\section{Survey Instruments}

All the items in the survey were measured on a 5-point Likert scale ranging from (1) strongly agree to (5) Strongly Disagree. All items were adopted from scales developed by their respective authors. 


\section{Measures}

\section{Individual Level Instruments}

\section{Inclusive Leadership}

Inclusive leadership is measured by adopting 9-items from the scale developed by Carmeli et al. (2010) with Cronbach alpha of 0.938.

\section{Interpersonal Relationships}

Interpersonal relationships are measured by adopting 10-items from the scale developed by May et al. (2004) with Cronbach alpha of 0.907.

\section{Adherence to Norms}

Adherence to norms is measured using the 3-item scale developed by May et al. (2004) with Cronbach alpha of .759 .

\section{Group Level Instruments}

\section{Affect-Based Trust}

Affect-based trust is measured by adopting 4-items from the scale developed by McAllister (1995) with Cronbach alpha of 0.864.

\section{Team Autonomy}

Team autonomy is measured by adopting 4-items from the scale used by Chandrasekaran and Mishra (2012) with Cronbach alpha of 0.905.

\section{Inclusive Leadership}

Inclusive leadership is measured using the 3-items scale of Nembhard and Edmondson (2006) with Cronbach alpha of 0.871.

\section{Team Structure}

Team structure is measured using the 5-item scale developed by Bunderson and Boumgarden (2010) with Cronbach alpha of 0.865 .

\section{Organizational Context Support}

Organizational context support is measured using 5-item scale developed by A. Edmondson (1999) with Cronbach alpha of 0.659. 


\section{Organizational Level Instruments}

\section{High-Quality Relationships}

High-quality relationship is measured by adopting the 20-item scale used by Carmeli et al. (2009). In this scale, 5 items measure emotional carrying capacity, 4 items measure tensility, 4 items measure connectivity, 3 items measure positive regard and 4 items measure mutuality with Cronbach alpha values of $0.878,0.916,0.909,0.895$ and 0.864 respectively.

\section{Psychological Safety}

The individual and organizational level scales used to measure psychological safety (Detert \& Burris, 2007; Baer \& Frese, 2003) were both originally adopted from the group level scale developed by A. Edmondson (1999).

\section{Results}

Table 1
\begin{tabular}{lccccc} 
Means, Standard Deviation and Intercorrelation \\
\hline Variables & $\mathbf{M}$ & SD & $\mathbf{1}$ & $\mathbf{2}$ & $\mathbf{3}$ \\
\hline Inclusive Leadership & 2.1 & 0.59 & & & \\
Interpersonal Relationships & 2.2 & 0.53 & $.503^{* *}$ & & \\
Adherence to Norms & 3.7 & 0.54 & $-.267^{*}$ & $-.414^{* *}$ & \\
Psychological Safety & 2.5 & 0.51 & $.588^{* *}$ & $.550^{* *}$ & $-.349^{* *}$ \\
\hline **. Correlation is significant at the 0.01 level (2-tailed). & \\
*. Correlation is significant at the 0.05 level (2-tailed).
\end{tabular}

To test the hypotheses, multiple regression analysis was conducted on individual, group and organizational level datasets. The means, standard deviation, correlation and the regression results for the individual level antecedents are presented in Table 1 and Table 2.

The results in table 1 indicate a positive correlation of inclusive leadership, interpersonal relationships with psychological safety $(\mathrm{r}=.558, \mathrm{p}<0.01$, for IL and PS) and $(\mathrm{r}=.550$, $\mathrm{p}<0.01$ for PS and IR). However, as hypothesized adherence to norms has a negative correlation with psychological safety $(\mathrm{r}=-.349, \mathrm{p}<0.01)$. Adherence to norms was also negatively correlated with inclusive leadership $(\mathrm{r}=-.267, \mathrm{p}<0.05)$ and interpersonal relationships $(\mathrm{r}=-.414, \mathrm{p}<0.01)$. Thus, hypothesis (h1a, h1b, h1c \& h1d) are accepted. Furthermore, in table 2, when psychological safety was predicted it was found that, inclusive leadership $(\beta=.353, \mathrm{p}<0.001)$, interpersonal relationships $(\beta=.288, \mathrm{p}<0.001)$ and adherence to norms $(\beta=-.112, \mathrm{p}<0.001)$ were significant predictors. The overall model fit was $R^{2}=.443$ 
Table 2

Regression Analysis

\begin{tabular}{lcccc}
\hline IV & $\beta$ & $R^{2}$ value & F & sig \\
\hline Inclusive Leadership & 0.353 & & & 0.000 \\
Interpersonal Relationships & 0.288 & 0.443 & 21.249 & 0.005 \\
Adherence to Norms & -0.112 & & & 0.004 \\
\hline
\end{tabular}

Table 3 and 4 contains the means, standard deviation, correlation and regression analysis for group level antecedents.

Table 3

Means, Standard Deviation and Intercorrelation

\begin{tabular}{lccccccc}
\hline Variable & M & SD & $\mathbf{1}$ & $\mathbf{2}$ & $\mathbf{3}$ & $\mathbf{4}$ & $\mathbf{5}$ \\
\hline Affect-Based Trust & 2.64 & 0.41 & & & & & \\
Inclusive Leadership & 2.49 & 0.46 & $.480^{* *}$ & & & & \\
Team Autonomy & 2.52 & 0.53 & $.286^{* *}$ & $.385^{* *}$ & & & \\
Team Structure & 2.53 & 0.62 & $.439^{* *}$ & $.271^{*}$ & $.469^{* *}$ & & \\
Organizational Context Support & 2.62 & 0.34 & $.453^{* *}$ & $.419^{* *}$ & $.356^{* *}$ & $.227^{*}$ & \\
Team Psychological Safety & 2.85 & 0.37 & $.585^{* *}$ & $.658^{* *}$ & $.584^{* *}$ & $.501^{* *}$ & $.572^{* *}$ \\
\hline **. Correlation is significant at the 0.01 level (2-tailed). & & & & \\
*. Correlation is significant at the 0.05 level (2-tailed). & & & &
\end{tabular}

The correlation results (table 3 ) shows that affect-based trust $(\mathrm{r}=.585, \mathrm{p}<0.01)$, inclusive leadership $(\mathrm{r}=.658, \mathrm{p}<0.01)$, team autonomy $(\mathrm{r}=.584, \mathrm{p}<0.01)$, team structure $(\mathrm{r}=.501$, $\mathrm{p}<0.01)$ and organizational context support $(\mathrm{r}=.572, \mathrm{p}<0.01)$ are positively and significantly related with team psychological safety. Thus, the hypotheses (h2a, h2b, h2c, h2d $\& \mathrm{~h} 2 \mathrm{e}$ ) are accepted. Hypothesis (h2f) is also accepted as all the antecedents are positively related with one another. Moreover, when team psychological safety was predicted (table 4) affect-based trust $(\beta=.160, \mathrm{p}<0.05)$, inclusive leadership $(\beta=.274, \mathrm{p}<0.001)$, team autonomy $(\beta=.174, \mathrm{p}<0.001)$, team structure $(\beta=.098, \mathrm{p}<0.05)$ and organizational context support $(\beta=.242, \mathrm{p}<0.001)$ were significant predictors. The overall model fit was $R^{2}=.682$.

The means, standard deviation, correlation and regression analysis for organizational level antecedents are presented in table 5 and 6.

The results in table 5 indicate that the capacities $(\mathrm{r}=.539, \mathrm{p}<0.01)$ and the experiences $(\mathrm{r}=.412, \mathrm{p}<0.01)$ are positively and significantly influence psychological safety. Therefore, the hypotheses (h3a \& h3b) are accepted and when climate for psychological safety was predicted both capacities of HQR $(\beta=.351, \mathrm{p}<0.001)$ and experiences of HQR $(\beta=.137$, $\mathrm{p}<0.05)$ were significant predictors. The overall model fit was $R^{2}=.557$.

Table 4

Regression Analysis

\begin{tabular}{lcccc}
\hline IV & $\beta$ & $R^{2}$ value & F & sig \\
\hline Affect-Based Trust & 0.16 & & & 0.033 \\
Inclusive Leadership & 0.274 & & & 0.000 \\
Team Autonomy & 0.174 & 0.682 & 33.459 & 0.002 \\
Team Structure & 0.098 & & & 0.038 \\
Organizational context support & 0.242 & & & 0.004 \\
\hline
\end{tabular}


Table 5

Means, Standard Deviation and Intercorrelation

\begin{tabular}{lcccc}
\hline Variables & M & SD & $\mathbf{1}$ & $\mathbf{2}$ \\
\hline Capacities & 2.56 & 0.71 & & \\
Experiences & 2.43 & 0.68 & $.547^{* *}$ & \\
Climate for Psychological Safety & 2.8 & 0.56 & $.539^{* *}$ & $.412^{* *}$ \\
\hline
\end{tabular}

\begin{tabular}{lcccc}
$\begin{array}{l}\text { Table } 6 \\
\text { Regression Analysis }\end{array}$ & & & & \\
\hline IV & $\beta$ & $R^{2}$ value & F & sig \\
\hline Capacities of HQR & 0.351 & 0.557 & 18.202 & 0.000 \\
Experiences of HQR & 0.137 & & & 0.035 \\
\hline
\end{tabular}

\section{Discussion}

\section{Individual-level Discussion}

The findings revealed that, inclusive leadership and interpersonal relationships were significantly associated with psychological safety. The results thus indicate that inclusive leadership and interpersonal relationships strongly influence the individual beliefs about speaking up, proposing ideas or asking questions. When employees felt that their leaders invited their input, was accessible and available, it allowed them to openly share their views, ideas and reduce the fear of facing any consequences that may arise from speaking up, effectively creating safety in the workplace, indeed, when leaders display availability, openness, and accessibility are likely to further the development of psychological safety in the workplace (Carmeli et al., 2010). Similarly, when the relationships between the coworkers were based on trust and the beliefs that the coworkers value each other's opinions and ideas, it helped create feelings of psychological safety in the individuals. While the above factors had a positively influenced psychological safety, adherence to norms was negatively impacted psychological safety. Consequently, when employees were expected to conform to existing norms they felt less psychologically safety, as pre-existing norms may not allow individuals (especially new employees) to challenge the views of older/senior employees thus increasing the probability of employees staying silent and not speaking up (May et al., 2004).

\section{Group-level Discussion}

When group members felt that they could trust and feel an emotional bond between themselves and their leader (affect-based trust), the more freedom they had in taking routine decisions, freely communicate with one another, plan and manage their work (team autonomy), the belief that their leader appreciated and invited the employees contributions (inclusive leadership) helped create psychologically safety in the group.

Similarly, the study concluded that when there was high clarity in the roles to be performed, procedures and authority in the group (team structure), and the belief of the 
group that they received adequate resources and information (organizational context support), helped eliminate the insecurities felt by the members and developed psychological safety in the group. High clarity in roles, priorities and procedures and authority makes the team member interactions very predictable while removing uncertainty foster intragroup trust (A. C. Edmondson, 2004; Bunderson \& Boumgarden, 2010).

\section{Organizational-level Discussion}

The findings of the study suggest that positive relationships in the workplace are important mechanisms that influence the individual's perceptions regarding psychological safety. Specifically, the researchers found that the capacities of high-quality relationships (emotional carrying capacity, tensility, and connectivity) and the subjective experiences (positive regard and mutuality) felt by the individuals in such relationships were significantly affected climate for psychological safety. Hence, when the quality of the relationships between organizational members are high, they feel more psychologically safe, reinforcing previous research on high-quality relationships and climate for psychological safety (Dutton \& Heaphy, 2003; Carmeli et al., 2009).

\section{Conclusion}

The researchers believe that psychological safety is especially important in today's context because it enables organizational learning and improves work outcomes at any level of analysis. This research identifies workplace factors that are associated with psychological safety and provide an incentive to the managers to engage in supportive leadership behaviors, creating strong bonds between the organizational members and leverage organizational practices to develop psychological safety at their workplace.

\section{Implications for Practice}

In today's organizational life working collaboratively is an essential part, but it quite often proves to be more interpersonally difficult than anticipated. The most common challenge faced by organizations are managing the interpersonal threats inherent in employees expressing uncertainty, voicing concerns and opinions. These threats are subtle but powerful, and they inhibit organizational learning. For people to feel comfortable in speaking up with ideas or questions - an essential aspect of organizational learning without fear of ridicule or punishment, managers must work to create a climate of psychological safety. Otherwise, the interpersonal risk is a powerful force that makes effective collaboration less likely to occur, particularly when the work is characterized by uncertainty and complexity. However, the burden of collaborating and learning does not lie solely with managers. Employees can help by taking specific actions that differ in important ways from conventional wisdom about ideal employee behavior. For example, most managers would naturally value an employee who solves problem he/she encounters without concerning their manager or colleagues, that is, without speaking up, asking for help, or 
questioning how and why the problem occurred in the first place.

Clearly understanding the benefits of psychological safety, the conditions in which psychological safety is very influential, and the factors that lead to the development of psychological safety will help the leader to design work environments that increase the favorable organizational outcomes. Psychological safety is worthy for the success of an organization, especially in the current business environment, given that employees are required to share and exchange ideas and information with other organizational members and teams to attain organizational goals.

\section{Limitations and Future Research}

The findings of this study shall be dealt with caution as it is not without limitations. Firstly, this study is cross-sectional and based on self-reported data collected using questionnaires. The use of such a tool may lead to several shortcomings (1) social desirability bias; (2) questionnaires measure the respondents' attitudes, not the actual behavior. This can be addressed by employing mixed methodologies in research studies as suggested by Tehseen, Ramayah, and Sajilan (2017). Also, quantitative survey methodology has been extensively used in past research, so it is advised to the researchers to use alternative methodologies in future work to understand more deeply how psychological safety is developed in the organization. In addition, to qualitative interview methodologies, researchers may consider using observation techniques to measure the psychological safety of a team or in a dyadic context. Future researchers may conduct a longitudinal research that allows both a better assessment of cause and effect and an examination of changes in psychological safety over time. Finally, this study was an attempt to study the relationships of psychological safety at several levels, however, it was not linked to any employees' outcomes. Therefore, it is recommended for upcoming researchers to consider testing the relationships of psychological safety with employees' outcomes in the form of work motivation, job satisfaction, organizational commitment and turnover intention (Adil, Owais, \& Qamar, 2018; Naeem, Jamal, \& Riaz, 2017). 


\section{References}

Adil, M. S., Owais, M., \& Qamar, A. (2018). Impact of occupational stress, interpersonal trust, and organizational commitment on valence, ocb and job satisfaction: A variance-based SEM analysis. Journal of Management Sciences, 5(1), 38-61.

Baer, M., \& Frese, M. (2003). Innovation is not enough: Climates for initiative and psychological safety, process innovations, and firm performance. Journal of Organizational Behavior: The International Journal of Industrial, Occupational and Organizational Psychology and Behavior, 24(1), 45-68.

Barker, J. R. (1993). Tightening the iron cage: Concertive control in self-managing teams. Administrative Science Quarterly, 38(3), 408-437.

Bass, B. M., \& Stogdill, R. M. (1990). Bass \& Stogdill's handbook of leadership: Theory, research, and managerial applications. United States: Simon and Schuster.

Bordovskaia, N. V., \& Baeva, I. A. (2015). The psychological safety of the educational environment and the psychological well-being of Russian secondary school pupils and teachers. Psychology in Russia, 8(1), 86-99.

Brown, S. P., \& Leigh, T. W. (1996). A new look at psychological climate and its relationship to job involvement, effort, and performance. Journal of Applied Psychology, 81(4), 358-368.

Bunderson, J. S., \& Boumgarden, P. (2010). Structure and learning in self-managed teams: Why "bureaucratic" teams can be better learners. Organization Science, 21(3), 609_ 624.

Carmeli, A., Brueller, D., \& Dutton, J. E. (2009). Learning behaviours in the workplace: The role of high-quality interpersonal relationships and psychological safety. Systems Research and Behavioral Science: The Official Journal of the International Federation for Systems Research, 26(1), 81-98.

Carmeli, A., Reiter-Palmon, R., \& Ziv, E. (2010). Inclusive leadership and employee involvement in creative tasks in the workplace: The mediating role of psychological safety. Creativity Research Journal, 22(3), 250-260.

Chandrasekaran, A., \& Mishra, A. (2012). Task design, team context, and psychological safety: An empirical analysis of R\&D projects in high technology organizations. Production and Operations Management, 21(6), 977-996.

Chen, C., Liao, J., \& Wen, P. (2014). Why does formal mentoring matter? The mediating role of psychological safety and the moderating role of power distance orientation in the Chinese context. The International Journal of Human Resource Management, 25(8), 1112-1130.

Detert, J. R., \& Burris, E. R. (2007). Leadership behavior and employee voice: Is the door really open? Academy of Management Journal, 50(4), 869-884.

Dutton, J., \& Heaphy, E. (2003). The power of high-quality relationships at work. Positive Organizational Scholarship, 263-278.

Edmondson, A. (1999). Psychological safety and learning behavior in work teams. Administrative Science Quarterly, 44(2), 350-383.

Edmondson, A. C. (2004). Learning from mistakes is easier said than done: Group and organizational influences on the detection and correction of human error. The Journal 
of Applied Behavioral Science, 40(1), 66-90.

Edmondson, A. C., Bohmer, R. M., \& Pisano, G. P. (2001). Disrupted routines: Team learning and new technology implementation in hospitals. Administrative Science Quarterly, 46(4), 685-716.

Edmondson, A. C., Kramer, R. M., \& Cook, K. S. (2004). Psychological safety, trust, and learning in organizations: A group-level lens. Trust and Distrust in Organizations: Dilemmas and Approaches, 12, 239-272.

Edmondson, A. C., \& Lei, Z. (2014). Psychological safety: The history, renaissance, and future of an interpersonal construct. Annu. Rev. Organ. Psychol. Organ. Behav., 1(1), 23-43.

Feldman, D. C. (1984). The development and enforcement of group norms. Academy of Management Review, 9(1), 47-53.

Hans, S., \& Gupta, R. (2018). Job characteristics affect shared leadership: The moderating effect of psychological safety and perceived self-efficacy. Leadership E Organization Development Journal, 39(6), 730-744.

Janis, I. L. (1982). Groupthink: Psychological studies of policy decisions and fiascoes. Boston: Houghton Mifflin Boston.

Kahn, W. A. (1990). Psychological conditions of personal engagement and disengagement at work. Academy of Management Journal, 33(4), 692-724.

Liu, W., Zhang, P., Liao, J., Hao, P., \& Mao, J. (2016). Abusive supervision and employee creativity: The mediating role of psychological safety and organizational identification. Management Decision, 54(1), 130-147.

May, D. R., Gilson, R. L., \& Harter, L. M. (2004). The psychological conditions of meaningfulness, safety and availability and the engagement of the human spirit at work. Journal of Occupational and Organizational Psychology, 77(1), 11-37.

McAllister, D. J. (1995). Affect-and cognition-based trust as foundations for interpersonal cooperation in organizations. Academy of Management Journal, 38(1), $24-59$.

Mogelof, J. P., \& Edmondson, A. C. (2006). Explaining psychological safety in innovation teams: Organizational culture, team dynamics, or personality? In Creativity and innovation in organizational teams (pp. 129-156). Psychology Press.

Naeem, M., Jamal, W., \& Riaz, M. K. (2017). The relationship of employees' performance appraisal satisfaction with employees' outcomes: Evidence from higher educational institutes. FWU Journal of Social Sciences, 11(2), 71-81.

Nembhard, I. M., \& Edmondson, A. C. (2006). Making it safe: The effects of leader inclusiveness and professional status on psychological safety and improvement efforts in health care teams. Journal of Organizational Behavior: The International Journal of Industrial, Occupational and Organizational Psychology and Behavior, 27(7), 941-966.

Roussin, C. J. (2008). Increasing trust, psychological safety, and team performance through dyadic leadership discovery. Small Group Research, 39(2), 224-248.

Roussin, C. J., \& Webber, S. S. (2012). Impact of organizational identification and psychological safety on initial perceptions of coworker trustworthiness. Journal of Business and Psychology, 27(3), 317-329.

Schaubroeck, J., Lam, S. S., \& Peng, A. C. (2011). Cognition-based and affect-based trust as mediators of leader behavior influences on team performance. Journal of Applied 
Psychology, 96(4), 863-871.

Schein, E. (1985). Organization culture and leadership. San Francisco: Josey-Bass.

Schein, E. H., \& Bennis, W. G. (1965). Personal and organizational change through group methods: The laboratory approach. United States: Wiley.

Stewart, G. L. (2006). A meta-analytic review of relationships between team design features and team performance. Journal of Management, 32(1), 29-55.

Tehseen, S., Ramayah, T., \& Sajilan, S. (2017). Testing and controlling for common method variance: A review of available methods. Journal of Management Sciences, 4(2), 142 168.

Thau, S., Bennett, R. J., Mitchell, M. S., \& Marrs, M. B. (2009). How management style moderates the relationship between abusive supervision and workplace deviance: An uncertainty management theory perspective. Organizational Behavior and Human Decision Processes, 108(1), 79-92.

Van Dyne, L., \& LePine, J. A. (1998). Helping and voice extra-role behaviors: Evidence of construct and predictive validity. Academy of Management Journal, 41(1), 108-119.

Wageman, R. (1996). The effects of team design and leader behavior on self-managing teams: $A$ field study (Tech. Rep.). Working paper, Columbia University, New York.

Weick, K. E., \& Roberts, K. H. (1993). Collective mind in organizations: Heedful interrelating on flight decks. Administrative Science Quarterly, 38(3), 357-381.

West, M. A. (1990). The social psychology of innovation in groups. Oxford, England: John Wiley \& Sons.

Wheelwright, S. C. (1994). Leading product development: The senior manager's guide to creating and shaping. United States: Simon and Schuster.

Yin, R. (1993). Applications of case study research. Beverly Hills, CA: Sage Publishing. 